\title{
EDITORIAL
}

\section{Psychology Journals: Proposal for Financial Disclosure Policies}

\author{
Gerald Young
}

Received: 6 April 2009/Accepted: 15 April 2009/Published online: 22 May 2009

(C) Springer Science + Business Media, LLC 2009

\begin{abstract}
All psychology journals should require that authors and reviewers abide by the policy of complete disclosure of conflicts of interest. The scientific and medical research publishing communities have been shaken by cases of lack of appropriate disclosure, leading to the development of editorial disclosure policies. The American Psychological Association requires full disclosure by authors who submit manuscripts to its journals. Medical journals have elaborate policies related to financial disclosure. In the area of forensics, it is especially important to have clear financial disclosure policies. With this editorial, the journal is spearheading efforts to encourage psychological and psychiatric journals with a forensic focus to adopt uniform, comprehensive, strict financial disclosure policies. Other psychology journals should consider the issues, as well. Recommendations concerning specific financial disclosure policies that journals could adopt are offered.
\end{abstract}

Keywords Editorial policies · Financial disclosure

The American Psychological Association (APA) publishes many psychological journals and requires that authors fully disclose conflicts of interests by filling out an explicit form (available at www.apa.org/journals/authors/disclosure of_interests.pdf). The one-page form indicates that all psychological publications should be based on "objective interpretations of evidence and unbiased interpretations of fact." In this regard, any economic and commercial interests that might "color" or "distort" the authors' objectivity

G. Young $(\bowtie)$

Department of Psychology, Glendon College, York University,

2275 Bayview Ave.,

Toronto, ON M4N 3M6, Canada

e-mail: gyoung@glendon.yorku.ca should be disclosed, even in cases in which authors maintain that there is no such conflict or bias. One example included on the APA form is the case in which an author is the copyright holder for and/or the recipient of royalties from a psychological test. In cases such as these, full disclosure is required. Similarly, authors should disclose any "bias against a product, service, facility, or person." An appropriate example would be where an author has a copyright or royalty interest in a psychological test or assessment protocol that is the competitor of one being criticized.

Other journals, such as Psychological Injury and Law (PIL), have adopted this disclosure policy (Young 2009). In addition, the journal emphasizes the need to disclose specifics of grants, disbursements, gifts, noncompetitive financial sources, or other financial underwriting of manuscript submissions and of research undertaken. For example, plaintiff and defense sides of the legal divide might provide monies for research projects and to authors, and these funding sources should be fully disclosed. PIL also requires that reviewers adhere strictly to these disclosure policies. Finally, the journal trusts the veracity of author disclosures, unless available evidence indicates that further investigation is needed.

Medical journals have spearheaded efforts to promote effective disclosure policies, but striking examples of these policies having been ignored or circumvented have appeared in the media. There are recurrent examples of pharmaceutical companies paying medical doctors to help in their research, without the doctors disclosing the source of funding in their publications. This has generated much embarrassment for the journals involved, the medical field, and science in general.

However, the quality of the medical disclosure policies cannot be faulted. The difficulties lie with the researchers 
involved. This being said, without adequate disclosure policies, journals in psychology are both ignoring important issues and opening themselves to the same type of problems that have developed in the medical research publications.

In 1984, The New England Journal of Medicine (NEJM) began requiring authors to disclose conflicts of interest (Drazen and Curfman 2002; downloaded April 2, 2009), and other medical journals have followed suit. The disclosure policies are considered guidelines rather than rigid rules. For NEJM, submitted manuscripts must be free of biasing commercial or financial influence within 2 years of the publication date. Authors need to disclose industry-related consulting fees, honoraria, grants, advisory board membership, equity ownership or options to own (whether in publicly or privately traded companies), patent royalties, and fees for expert testimony. If the manuscript is a review, for example, about a new drug therapy, the authors do not have to disclose a minor financial interest deriving from an association with the company involved or with a competitor, but the authors cannot have a significant financial interest in any such company (the threshold is $\$ 10,000$ annually; at first, the policy had required disclosure of even minor financial interest, but as a result submissions were greatly curtailed!).

The British Medical Journal (BMJ 2009, http://content. nejm.org/cgi/content/full/346/24/1901) requires both authors of submissions and reviewers to disclose conflicts of interest, and it uses the same description and examples for both. BMJ asks especially for disclosure of financial "competing" interests, which arise when secondary interests, such as financial gain, might influence professional judgment about the validity of the submitted manuscripts or might influence other primary interests. Potential authors and reviewers are requested to list any stocks or shares owned, and salaries, staff member payments, reimbursements, fees, or funds received involving organizations that may be affected financially (either positively or negatively) by submitted manuscripts. In addition, potential authors and reviewers are asked whether they have served as expert witnesses on the topic of the submitted manuscripts. The time frame for listing competing interests such as these involves the 5-year period preceding the time of the disclosure.

Through the comparison of these two major medical journals with respect to their financial disclosure policies, it becomes evident that the policies are evolving, there is no one standard, and they present difficulties to authors. The financial disclosure policies in this editorial are presented through vignettes so that potential conflicts of interest are couched in possible real-life contexts. This may help researchers ponder better the issues, compared to the typical checklist format.

Therefore, in this editorial, I expand conflict of interest and disclosure policies by elaborating upon ten vignettes that present particular practice and ethical dilemmas involving financial disclosure. These examples are straightforward in illustrating situations in which full financial disclosure is necessary and the problems that can develop when authors, reviewers, and editors do not adhere to the strictest of professional and disclosure practices in these regards. At the end of each of the ten vignettes, the editorial specifies the principle pertaining to financial disclosure in conducting research and in publishing. The editorial provides specific recommendations about the details of financial disclosure policies that journals could adopt. The conclusions of the editorial emphasize that forensic psychology and related journals, as well as other journals, should coordinate the implementation of uniform and comprehensive, strict practices, such as those presented.

\section{Ten Vignettes and Principles Related to Financial Disclosure}

1. A young psychologist has published her doctoral thesis on the topic of a leading psychological test. She is approached by the test publisher and asked to undertake further research on the test in order to publish it in academic publications in the area. She is paid a handsome fee. However, as per the conditions involved, she conducts the research with the publisher's database, with ghost statisticians and ghost writers doing most of the work, with no access to the database allowed, with no disclosure of the relationship to the company permitted, with the ghost writers having final say on her modifications to the manuscript, and with the company determining avenue of publication.

Principle 1. Researchers in the forensic disciplines should avoid scrupulously any underhanded financial relationships with industry.

2. A senior psychologist who has published extensively on the topic of a particular test does not disclose all the financial advantages that his research brings to him through the work. He does cite the source of his funding, for example, through the test company, and he indicates that he testifies on the validity of the test in court for plaintiff (defense, as the case may be). However, other parts of his financial remuneration related to his dealings with the test company are left out (e.g., paid flights and accommodations at conferences; his son is given a job at the test company).
Principle 2. In disclosing financial conflicts of interest, researchers in forensics should be open and complete.

3. A researcher in the area of forensics has a private practice in which he usually undertakes evaluations for plaintiff (defense, as the case may be). He is the author of a psychological test used for court purposes. He adopts a 
strong point of view on the value of his test in his publications. At the same time, he gets paid a handsome fee when he testifies in court about the test. He does not disclose his forensic work in the disclosure statements in his publications.

Principle 3. In making full financial disclosure about forensic research, the benefits accruing to one's practice should be specified, as well.

4. A practitioner in the area of forensics decides to do targeted research to help with his testimony in court. In his publications, he presents the research in an apparently impartial manner. However, he fails to disclose that he approached leaders in the industry involved in the subject of his research (toxic products) and obtained funding on the premise that the research would support their point of view. Moreover, he failed to disclose the source of funding for the research. He makes a lot of money testifying for the industry in court.

Principle 4. Hiding one's financial benefits deriving from forensic research risks leaving the individual exposed to loss of reputation and even career.

5. A senior psychologist serves in a paid board position for an insurance company, and simultaneously both publishes research in scholarly journals about personal injury lawsuits and provides forensic consultations with respect to psychological injury claims. This information is not disclosed in publications, presentations, workshops, testimony, and so forth.

Principle 5. To make full financial disclosure about one's forensic practice, even more indirect linkages should be specified.

6. A psychologist conducts comprehensive disability evaluations for a large Mental Health Organization (MHO) that is owned by an insurance company. The senior managers of the MHO ask her to examine patient files in order to determine what factors influence outcomes in disability and return to work. She gets other psychologists who work with other such companies to contribute patient data to her database. In her publications, she fails to disclose the industry link, worrying that disclosure will reveal that she succumbed to industry pressure.

Principle 6. In conducting forensic psychological research, there are work pressures deriving from employment in large organizations that need prudent consideration. All such employment must be disclosed in publications.

7. A psychiatrist is hiring psychiatrists and psychologists to work for the mental health sector of a large health service provider. As a condition of being hired, he asks them to participate in his research on the effectiveness of a powerful anti-psychotic for which he receives funding from a large pharmaceutical company. The psychiatrist does not disclose the connection in his publications, and the co-authors do not raise the issue with him.

Principle 7. Even second and other authors of forensic research publications must fully disclose financial conflicts of interest.

8. An attorney helps the state defense lawyer's association to which he belongs argue for new laws to regulate the state automobile insurance system. The state hopes to move toward no-fault insurance and has data from those jurisdictions where it has been implemented showing that it is cost-effective and efficient. The attorney publishes articles with psychologists indicating the contrary, does not cite the data to which he had access, and does not disclose that he is planning to switch to plaintiff rather than defense work. Later, when the information surfaces, the psychologists, as much as the attorney, are criticized in the local press.

Principle 8. Authors in the legal community working in the area are no less subject to the requirements to fully disclose financial conflicts of interest when publishing in journals requiring full financial disclosure.

9. A psychologist serves as an independent reviewer for a manuscript submitted to a forensic psychology journal. The paper concerns a leading psychological test that the authors had developed, and complete financial disclosure is provided by the authors. The reviewer has developed a test that is different from and competes with the one touted in the manuscript. She recommends rejection of the manuscript, but the reviewer does not disclose to the editor of the journal her own financial conflicts of interest (she would lose income if the other test were used more frequently than her own).

Principle 9. Reviewers of submissions to forensic journals are under the same obligation to fully disclose financial conflicts of interest.

10. An editor of a psychological journal dealing with forensics receives a submission to the journal from an author noted for contentious opinions. He finds that there is sufficient disclosure in the author notes but holds a point of view opposite to that of the author on the matter at hand. The editor undertakes an exhaustive search of various law search engines and finds testimony at one trial that might be appropriate to include in a statement of financial disclosure. Claiming that he has undertaken due diligence about disclosure 
and conflict of interest, he indicates to the author that he is declining to send out the submission for independent review to the journal's editorial board.

Principle 10. Editors of forensic journals bear the similar obligation to fully disclose all financial conflicts of interest and to behave in the utmost impartial manner in running their journals.

\section{Recommendations}

Some issues to consider in elaborating specific editorial policies about financial disclosure include (a) the sources of monies, (b) the specific work or representation undertaken for the sources, (c) whether actual amounts should be disclosed, (d) the relative amounts involved in disclosed and other income, (e) the thresholds for considering the amount significant rather than de minimus, (f) the number of years prior to the disclosure that should be considered, and (g) and projected financial considerations after the disclosure. (h) There is also the question of whether reviewers should disclose in the same way as authors and, if so, how the information should be used. The few specific examples that have been presented in the editorial from the medical field have both elucidated this range of issues and indicated that there is no consensus.

(a) In medical research, the primary sources of financial conflicts of interest relate to pharmaceutical companies and biomedical research where financial profits can accumulate. With respect to financial disclosure, in the area of psychology, insurance companies and test companies play an equivalent role. In terms of testifying in court, psychologists have the added potential influence of referral source in tort and related claims and their defense. These referral sources include attorneys, assessment houses, and public and private disability claims adjudicating venues (e.g., for work, military, social security).

The editorial recommends that in their publications researchers should report all sources of monies received that can possibly represent a financial conflict of interest. The journal reader and other audiences of the articles involved should have access to the full range of possible conflicts of interest, deciding for themselves whether the contents of the article have been influenced by the conflicts or whether the authors have presented unbiased work.

(b) The lists of types of monies that researchers can receive from organizations and other sources have been comprehensively enumerated by the medical journals. These types of remuneration include monies for salaries, representing the source, advisory board membership, consulting fees, honoraria for speaking or other functions, research grants or funding for other functions, equity ownership or options to own (stocks, shares; whether in publicly or privately traded companies), patent royalties, and fees for expert testimony. One could add to this list paid flights and subsistence fees for attendance at conferences or other functions. Note that all of the examples provided are of direct financial gains. There might be indirect ones, as well, such as having a family member placed on the payroll with little or nothing to do or getting honorarium fees for speaking at universities or national nongovernmental, nonprofit advocacy or patient groups or associations because of one's relationship with the sources.

(c-e) In the medical field, the amount of financial benefits deriving from association with or work for the types of sources mentioned can amount to millions of dollars. Typically, psychologists do not receive such amounts, which perhaps minimizes their exposure. However, conflicts of interest may arise even with the receipt of minor amounts from sources. Disclosure should be complete, whether minor or major, and that is the thrust of the policy of the American Psychological Association. However, unlike the case for medical journals, its policy does not qualify that the party has to reveal the exact amounts received or even the relative amounts (minimal, significant). This editorial maintains that full disclosure of financial conflicts of interest requires disclosure of even minor amounts. The party could reveal either the actual amount or the amount relative to other sources of income. Journals can specify thresholds such as $\$ 10,000$ as the dividing line between minimal or significant amounts received, but it may be preferable to have a more differentiated range, such as minimal, at threshold, moderate, major, and total. The latter would refer to whether all income derives from the types of sources mentioned. It is important to know this because a professional may receive a minor amount compared to the possible millions mentioned, but it may be all that they receive in a given year.

(f-g) In asking for disclosure, the medical journals specify the time frame for reporting the possible conflict of interest. However, of the two journals reviewed for their policies, one specifies a period of 2 years as the applicable period for disclosure and another 5 years. Moreover, one specifies that the disclosure period is applicable to the time frame prior to the publication date, whereas the other does not specify this, and we can assume that the time frame concerns the date the 
disclosure is made, such as at the time of submission of the manuscript. If there is a short time frame for the disclosure period, and the journal is characterized by a lengthy publication lag, with other loopholes possible, such as no requirement to report in the de minimus range, there are many avenues for real conflicts of interest that are possible but without reporting requirements, as a result of loosely configured policies. Moreover, the reasons for having a time frame for reporting possible conflicts of interest are not clear. For example, what if researchers had worked for a test company prior to the posted 5-year period and had conducted their research study described in the submitted manuscript in that time frame, but then the authors involved moved to university positions? If the policies of the journals allow loopholes in these regards, they could be used and lead to withholding of relevant disclosures.

In terms of time frame, it is also important to consider disclosure of future financial benefits. For example, in the medical field, there may be potential patents or patents that are pending that could reap large financial benefits, and this should be disclosed. In the psychological field, a researcher may have derived no financial benefit from an association with a test company, but large financial windfalls may be derived later from the test product being reported as reliable and valid in the submitted manuscript and then being published by the test company.

(h) The issue of whether reviewers should have the same obligation to report possible financial conflicts of interest raises difficulties that were pointed out by another editor of a forensic psychology journal. $\mathrm{He}$ indicated: Will reviewers receive the disclosure information when they receive blinded manuscripts? Will the disclosure compromise blindness? Or will reviewers not receive disclosure information and the editors will sort it out? If reviewers receive it, will they be instructed to comment on it? If blind reviewers disclose, will that compromise their blindness? Who sees reviewers' disclosure statements? The stance of this editorial with respect to these important issues in blind review is that, at present, there are no clear solutions, and reader input is appreciated to clarify any policy in these regards that should be implemented.

Finally, more work is needed on the ten vignettes that are at the heart of the current paper. Examples could be found that appear to contradict them, so that a good casebook may help. In this regard, one of the readers of an initial draft of the article pointed out instances where financial disclosure would not apply. For the first vignette, financial disclosure would not be called for in the case of manuscripts written for internal consumption at a test company. For the fifth vignette, there would be no need to disclose when one undertakes charity work for a nonprofit company, receiving some monies, but not enough to cover expenses for the work. He added examples where it might be impossible to predict future conflicts of interest. Also, in general, he did not want the field to have the perception that forensic work is more conflict-ridden than other domains.

\section{Conclusions}

Conflicts of interest can serve to undermine the credibility and the quality of published research, especially when they are not disclosed. Even when authors doubt the biasing effects of conflicts of interest, they should be disclosed so that the scientific community can decide on their influence, if any, on the research and the publications deriving from them. Conflicts of interest might jeopardize judgment, impartiality, objectivity, and conclusions offered but, potentially, they are mitigated or damped when their disclosure is offered in an open and complete manner.

When disclosure of financial interest or other conflicts of interest arise, the scientific community should not automatically assume that the research and publications involved are inevitably biased or somehow tainted. Psychologists confront ethical dilemmas quite complex in nature, and often handle them with dignity and aplomb. Psychologists and other professionals publishing in forensics should expect that their peers who disclose financial conflicts in their publications are aware of the potential biases. Many psychologists will handle the data deriving from studies where there are acknowledged conflicts of interest with impartiality and objectivity, arriving at reasoned and empirically based conclusions consistent with the literature and with theory in the area.

However, when it is evident that this is not the case, that the financial conflicts of interest have altered the unbiased perspective of the authors, and the resultant research and publications are more works of advocacy than products of scientific impartiality, the scientific community should evaluate the work with prudence, ascribing to it less importance. Indeed, the journals receiving submissions that lack the needed impartiality despite full financial and related disclosure should consider rejecting them, unless there are constraining factors. In this regard, when articles lack the needed impartiality, for example, they are part of an ongoing debate, the editors might decide to further place the debate in the public domain and publish the article at issue.

When impartiality is evident in a submission, and there is a known lack of financial disclosure that is pointed out by reviewers, the editor(s) should confront author(s) of the 
submission. If the author(s) refuse to include the required financial disclosure, the submission should be rejected. Another option is that the journal publishes the article, if the editorial board deems that the field will be served through the debate that the article will elicit, but the journal should add an accompanying editorial note about the financial disclosure issue at hand.

Journals in the area of forensic psychology and related disciplines have an obligation to the psychological and legal communities to publish articles that advance the science in the field and that help the law in its deliberations. Due to the nature of the field, articles that are published often are considered contentious. Whether contentious or not, it is possible to argue that the more that articles in the area provide full disclosure, including about financial matters, the less likely it is that they will be considered partial or biased by (a) readers, (b) psychologists writing rebuttals, (c) the scientific community, in general, and (d) triers of fact in court and related venues.

Of course, a counter-argument to having the field require full financial disclosure is that it could easily lead to the opposite of the desired effect. Upon reading the multiple disclosures that will be published once this policy is adopted uniformly by forensic psychology and related journals, the readers of these articles may be dismayed and conclude that the field is riddled with conflicts of interest.

In response to this possible negative outcome of having forensic psychology and related journals adopt a uniform policy of requiring full financial disclosure, this editorial argues the following. Acknowledging conflicts of interest is the first step in ensuring that one removes oneself as best as possible from their potential biases as one conducts research. The readers of the journal articles can decide to what extent the authors have succeeded in avoiding partiality and bias in their articles. Because researchers in the field all have some conflicts or biases, or most do, for example, at a minimum, one usually works one side of the legal divide more than the other, the argument can be made that once all authors publishing in the field engage in full disclosure, including at the financial level, the authors in the field become equalized this way, the playing field is leveled, and the field will be left primarily with the science to consider. Also, by disclosing, authors in the field avoid the glare of scrutiny that accompanies the uncovering of withheld information and which compromises their integrity, and journals will avoid post-publication calamities stemming from lack of disclosure.
In publishing this editorial, I acknowledge it as tentative, in particular, in terms of some of the unexplored issues that have been raised. Moreover, the editorial asks for feedback toward the development of a comprehensive, strict policy on financial and related disclosures, shoring up the field on these contentious matters. The journal offers to become the publication forum for exploring the issues in this editorial. For example, the editorial asks the editors of other forensicrelated journals, as well as editors of all APA and other psychology journals, medical and related journals, or other journals with interest in the type of policies described, to comment. This project is not directly part of the journal's mission statement but, for all forensic psychology and related journals, developing a uniform, strict, comprehensive policy on financial and related disclosure constitutes our obligation to the field.

Financial disclosure is becoming obligatory in the contemporary scientific and medical publishing landscape. The necessity to disclose all relevant conflicts of interest presents difficulties to authors, and it has led to curtailment of submissions to journals that have promulgated more detailed policies. Students in these professions need critical, early training in the required ethics underlying the policies. Only in this way will resistance to these necessary policies begin to diminish. Our total compliance with these policies will ensure that our patients and the public are protected from harm and that the disciplines involved stand in good stead.

Many thanks to: Ken Pope, Brian Cutler, Bill Koch, Bob Barth, and Andrew Kane for helpful comments on the text.

The author's work has been supported by course leaves granted by both Glendon College and York University and editorial grants from Springer Science + Business Media.

In terms of possible conflicts of interest, the author has obtained most of his attorney referrals and psycholegal referrals from plaintiff rather than defense attorneys and assessment companies.

\section{References}

BMJ (2009). Competing interests: Guidance for authors and reviewers. Author. [http://resources.bmj.com/bmj/authors/check lists-forms/competing-interests]

Drazen, J. M., \& Curfman, G. D. (2002). Editorial: Financial associations of authors. New England Journal of Medicine, 346 (24), 1901-1902.

Young, G. (2009). Psychological Injury and Law: Editorial policies from defamation to disclosure. Psychological Injury and Law, 2(1), 1-3. 